\title{
LA CLÁUSULA PENAL ABUSIVA Y EL REQUISITO DE LA DESPROPORCIÓN DE LA PENA
}

\section{Andrés Sánchez Herrero}

\author{
Universidad Austral \\ andres@sanchezherrero.com.ar
}

Recibido: $10 / 08 / 2020$

Aceptado: 29/09/2020

\section{Resumen}

Se analiza el requisito central del cual depende si una cláusula penal es o no abusiva (y, por ende, si debe o no ser reducida): su desproporción. A este efecto, debe dilucidarse si es proporcionada con el valor de la prestación o del resarcimiento que viene a sustituir. En consecuencia, a pesar de lo que dispone la ley, el acreedor no puede desentenderse del daño si la cláusula es cuestionada por el deudor. Si bien, en teoría, también se requiere que el acreedor se haya aprovechado abusivamente de la situación del deudor, este requisito es ignorado en la praxis judicial, lo que pone en evidencia la centralidad del daño en esta materia.

Palabras clave: cláusula penal, cláusula penal abusiva, requisitos, Código Civil y Comercial argentino, desproporción, daño resarcible.

\section{The Unfair Penalty Clause and the Requirement of Disproportionate Punishment}

\begin{abstract}
The central requirement on which depends whether or not a penalty clause is abusive (and therefore whether or not it should be reduced) is analysed: its disproportion. To this end, it must be determined whether it is proportionate to the value of the compensable damage it replaces. Consequently, notwithstanding the provisions of the law, the creditor cannot disregard the damage if the term is contested by the debtor. Although in theory the creditor is also required to have taken unfair advantage of the debtor's situation, this requirement is ignored in judicial practice, which highlights the centrality of the compensable damage in this matter.
\end{abstract}

Key words: penalty clause, abusive penalty clause, requirements, Argentine Civil and Commercial Code, disproportion, compensable damages. 


\section{Introducción}

En este artículo, analizaré el requisito central del cual depende la reducción de una cláusula penal abusiva en el derecho argentino: la desproporción.

A este efecto, primero haré una breve introducción a la cláusula penal en general. Luego, daré una visión panorámica del problema de la pena abusiva (noción, evolución histórica, sistemas comparados y estado de la cuestión en la Argentina). Finalmente, abordaré el objeto específico de este trabajo: el requisito de la desproporción (el elemento objetivo).

\section{La cláusula penal: noción y normativa aplicable}

De acuerdo con el artículo 790 del Código Civil y Comercial (CC), "[l]a cláusula penal es aquella por la cual una persona, para asegurar el cumplimiento de una obligación, se sujeta a una pena o multa en caso de retardar o de no ejecutar la obligación". ${ }^{1}$ Partiendo de esta base, la defino como el acto jurídico accesorio de una relación jurídica por el cual una persona se compromete a realizar una prestación (la pena) en caso de que el sujeto pasivo de esa relación incumpla su deber. Involucra tres objetos:

1) La cláusula penal, en sí. Es el acto jurídico definido.

2) La obligación principal. Es la relación jurídica cuyo incumplimiento se sanciona con la pena.

3) La pena. Es la sanción que nace de (1) para el caso de que se incumpla (2). Consiste en una prestación. Si no siempre, al menos sí en la mayoría de los casos.

Podría agregar un cuarto objeto: el acto jurídico del que nace la relación jurídica principal (2) y al que accede la cláusula penal (1). Pero no es necesario, si bien lo usual es que exista. De ser así, la cláusula penal suele integrarlo, aunque también es posible que se otorgue en forma independiente.

El instituto está regulado en la Sección 5a - "Obligaciones con cláusula penal y sanciones conminatorias"- del Capitulo 3 - "Clases de obligaciones"- del Título I -"Obligaciones en general"- del Libro tercero -"Derechos personales"- del CC.

La sección se extiende desde el artículo 790 hasta el 804. Salvo este último -que se refiere a las sanciones conminatorias-, el resto del articulado regula el funcionamiento de la cláusula penal.

1 La norma es copiada casi a la letra del artículo 652 del viejo CC, que, a su vez, se basaba en el artículo 1226 del Código Civil francés. 


\section{Sobre la pena abusiva en general \\ 3.1. Evolución histórica \\ 3.1.1. Evolución general}

En el derecho romano, en principio, la cláusula penal era absolutamente inmutable. No podía ser modificada unilateralmente por ninguna de las partes; tampoco por la autoridad. Sin embargo, se previó la reducción de los intereses usurarios.

En el antiguo derecho francés, en cambio, la cláusula penal era revisable, bien por excesiva o por insuficiente. Sin embargo, pasó a ser absolutamente inmutable a partir del Code, criterio que se irradió entre los demás códigos civiles y comerciales de la época.

En el derecho alemán ocurrió lo opuesto al francés. La cláusula penal, tradicionalmente inmutable, pudo y puede ser revisada a partir de la sanción de su Código Civil (BGB), tanto por exceso como por insuficiencia.

\subsubsection{Evolución en la Argentina}

\subsubsection{Código Civil originario}

Suele afirmarse que en el Código de Vélez la cláusula penal era absolutamente inmutable. Así resultaba de tres normas: los artículos 522, 655 y 656 (y, para algunos, también de una cuarta: el artículo 1189). ${ }^{2}$ Las normas disponían que la cláusula penal era inmodificable bajo cualquier circunstancia. Sin embargo, el artículo 660 establecía lo siguiente:

Si el deudor cumple sólo una parte de la obligación, o la cumple de un modo irregular o fuera del lugar o del tiempo a que se obligó, y el acreedor la acepta, la pena debe disminuirse proporcionalmente, y el juez puede arbitrarla si las partes no se conviniesen.

2 Disponían lo siguiente:

"Cuando en la obligación se hubiere convenido que si ella no se cumpliese se pagaría cierta suma de dinero, no puede darse una cantidad ni mayor ni menor" (Código Civil, artículo 522).

"La pena o multa impuesta en la obligación, entra en lugar de la indemnización de perjuicios e intereses, cuando el deudor se hubiese constituido en mora; y el acreedor no tendrá derecho a otra indemnización, aunque pruebe que la pena no es indemnización suficiente" (Código Civil, artículo 655).

"Para pedir la pena, el acreedor no está obligado a probar que ha sufrido perjuicios, ni el deudor podrá eximirse de satisfacerla, probando que el acreedor no ha sufrido perjuicio alguno" (Código Civil, artículo 656).

"Si en el instrumento público se hubiese estipulado una cláusula penal, o el contrato fuese hecho dándose arras, la indemnización de las pérdidas e intereses consistirá en el pago de la pena, y en el segundo en la pérdida de la señal, o su restitución con otro tanto" (Código Civil, artículo 1189). 
La norma admitía, entonces, la modificación de la pena. ${ }^{3}$ Más precisamente: la imponía ("la pena debe disminuirse").

Por lo tanto, la inmutabilidad de la pena no era absoluta. No quiero enredarme en cuestiones semánticas. En la sistematización que adopto, la previsión de una norma de este tipo implica que se ha adoptado un sistema de inmutabilidad relativa, en el que la regla general, efectivamente, es la intangibilidad de la pena, pero se admite alguna excepción. ${ }^{4}$

De todos modos, la modificación solo se admitía en este caso puntual y no dejaba de basarse, en definitiva, en el sentido o la voluntad subyacente a la propia cláusula penal. No se trataba de una "corrección" externa, sino, en el fondo, de un ajuste de lo formalmente estipulado a lo realmente querido. $\mathrm{O}$, si se quiere, de una subsunción adecuada del caso en la cláusula penal. Desde este punto de vista, entonces, puede afirmarse que en el Código de Vélez no se admitía una alteración basada en un criterio externo a lo estipulado (en un criterio correctivo).

Este era el panorama legal. Sin embargo, la jurisprudencia y la doctrina mitigaron con el tiempo el rigor de este principio. Echando mano de diversos dispositivos legales -el más socorrido, el artículo 953 del CC-, se terminó considerando que, por excepción, la pena se debía reducir si era desproporcionada con el incumplimiento y su secuela. ${ }^{5}$ El criterio se fue aplicando cada vez más, hasta que virtualmente dejó de ser excepcional.

\subsubsection{Código Civil reformado por la Ley 17711}

La Ley 17711 introdujo un cambio sustancial en el régimen de la cláusula penal. Si bien conservó las normas que consagraban la inmutabilidad de la pena, agregó este segundo párrafo al artículo 654:

Los jueces podrán, sin embargo, reducir las penas cuando su monto desproporcionado con la gravedad de la falta que sancionan, habida cuenta del valor de las prestaciones y demás circunstancias del caso, configuren un abusivo aprovechamiento de la situación del deudor.

3 Se basó en el artículo 1231 del Código Civil francés, según lo consignó Vélez en su nota.

4 Véase $\$ 3.2$.

5 Véanse Ameal y Belluscio (1981, pp. 217-218); Boffi Boggero (1973, p. 411); Llambías (1983, p. 445); Tale (2009, § I). 
Esto implicó una modificación radical del sistema legal, reflejo del cambio que ya se había operado a nivel doctrinario y jurisprudencial.

\subsubsection{Código Civil y Comercial}

El régimen de la cláusula penal del CC -hoy vigente- está casi calcado del previsto en el viejo CC tras su modificación por la Ley 17711.

\subsection{Sistemas ${ }^{6}$}

\subsubsection{Introducción}

Para que el panorama sea lo más abarcativo posible, avanzaremos en tres etapas:

1) En primer lugar, me referiré a los contratos de consumo y a los celebrados por adhesión.

2) Luego, al abordaje dispar que de los demás contratos hacen el sistema del common law y el continental europeo.

3) Finalmente, ya con relación a este último, distinguiré los distintos criterios que se aplican o han aplicado con respecto a la modificabilidad de la pena.

\subsubsection{Contratos de consumo y contratos celebrados por adhesión}

En líneas generales, las cláusulas penales que perjudican a los consumidores o adherentes se consideran inválidas. Este es el denominador común de las normas que regulan la cuestión en la mayoría de los ordenamientos jurídicos, que cada vez son más. Por supuesto, hay diferencias, pero tienden a coincidir en esta idea central.

El perjuicio típico consiste en imponerle al consumidor o adherente una pena o prestación de mayor entidad que la sanción que en virtud de las reglas generales le sería aplicable por el incumplimiento. Pero también puede consistir en que se le "impone" al proveedor o predisponente una "pena" cuyo valor es ostensiblemente menor que lo que debería pagar de acuerdo con el derecho común si incumpliese el contrato. En definitiva, una cláusula de exoneración o limitación de la responsabilidad, aunque camuflada. En general, los ordenamientos jurídicos protegen al consumidor o adherente en los dos casos.

En cuanto a la pena excesiva, en algunas legislaciones solo es inválida la

6 Véase Pizarro y Vallespinos (1999, pp. 75-76). 
pena que tiene una diferencia importante con lo que sería el resarcimiento aplicable en su lugar. En otros, en cambio, basta con que esta diferencia exista para que la cláusula sea ilegal, independientemente de su cuán grande sea. Basta con que la pena exceda lo que sería la sanción legal. Es nuestro caso. Es más, en algunos sistemas, se invalida la cláusula penal en sí por el mero hecho de ser tal, independientemente de su relación con lo que sería el daño resarcible de acuerdo con las reglas generales. Pero predomina el requisito del desequilibrio, en particular en los regímenes de defensa del consumidor. En cuanto a los de los contratos celebrados por adhesión, algunos ordenamientos adoptan este mismo criterio y otros solo invalidan la cláusula penal si el desajuste implica un desequilibrio injustificado en perjuicio del adherente, considerando el contrato en su integridad.

En cuanto a la pena insuficiente, el problema se presenta cuando su acreedor es el consumidor o adherente. Por lo general, se la considera ineficaz, en el sentido de que no vale como límite a lo que el consumidor o adherente tiene derecho a reclamar si el proveedor o predisponente incumple el contrato. Es el caso argentino.

En lo que hace a la sanción de las cláusulas abusivas, hay que distinguir dos cuestiones:

1) Cuando el problema es que se ha impuesto una pena excesiva al consumidor o adherente, la sanción suele ser la invalidez o nulidad de la cláusula. Por ende, incumplido el contrato, el proveedor o predisponente no puede hacerla valer, sin perjuicio de su derecho a ser resarcido de acuerdo con las reglas generales.

2) Cuando el problema es que se ha fijado una pena insuficiente al proveedor o predisponente, hay dos tipos de abordajes. Algunos ordenamientos invalidan la cláusula, de modo que el consumidor o adherente tiene derecho a ser resarcido de acuerdo con las reglas del derecho común. Otros, en cambio, le reconocen tanto el derecho a la pena como al resarcimiento del mayor daño que haya sufrido. Según entiendo, esto último es lo que ocurre en el derecho argentino.

\subsubsection{El common law y el derecho continental europeo}

En lo que hace a la cláusula penal, hay dos grandes abordajes en el derecho occidental: 
1) Sistema del common law

Solo son válidas las cláusulas de liquidación de daños (liquidated damages clauses o damages clauses), no las penas (penalties). Las primeras se pactan para compensar el daño que se derivará del eventual incumplimiento, no (como las segundas) para penalizar o castigar al incumplidor (por ejemplo, imponiéndole una prestación más gravosa que la que debería afrontar de acuerdo con las reglas ordinarias). Y el principal dato revelador de si la cláusula pertenece a una $\mathrm{u}$ otra categoría es la relación de valor entre la suma estipulada y el daño que al tiempo de la estipulación era previsible que el acreedor podría sufrir por el eventual incumplimiento: si los valores son proporcionados, es una cláusula de liquidación de daños; si no, una pena.

En definitiva, el sistema anglosajón corta por lo sano: si bien la adscripción de una cláusula determinada a una u otra categoría depende de su finalidad, al anclarla en el dato objetivo de si es o no proporcionada con el daño previsible, se termina erradicando la posibilidad de que la cláusula sea excesiva. Desde esta lógica, no tiene sentido plantearse la cuestión de su inmutabilidad: por definición, no es concebible que se pueda reducir una pena excesiva, ya que esta sería, lisa y llanamente, inválida. La estipulación es inmutable, sí, pero solo si es válida, y, para serlo, la suma debida no debe exceder al valor de los daños que fueron previsibles al estipularla.

\section{2) Sistema continental europeo}

Es en este sistema en el que es válida la cláusula que no es una mera estimación anticipada de los daños, que tiene sentido plantearse la cuestión de si cabe moderarla cuando es excesiva. En su versión decimonónica, la pena, aun siendo excesiva, era válida y no podía ser moderada. Hoy predomina la tendencia que faculta a los jueces para reducirla cuando es desproporcionada. Analizo los distintos sistemas en el parágrafo que sigue.

\subsubsection{Subsistemas del modelo continental europeo}

En términos teóricos, podemos distinguir dos subsistemas:

1) Sistema de la inmutabilidad absoluta

La cláusula penal no es modificable bajo ninguna circunstancia. Fue el adoptado por el derecho romano. 
2) Sistema de la inmutabilidad relativa

La cláusula penal es, en principio, inmodificable, pero, por excepción, puede llegar a serlo. En función de cuáles sean las excepciones que se admitan, es posible, a su vez, trazar otra subclasificación:

2.a) Sistema que admite la reducción de la pena por el cumplimiento parcial, defectuoso, irregular o inexacto de la obligación principal

De acuerdo con este sistema, solo se admite la modificación de la pena si, habiéndosela estipulado implícitamente para un incumplimiento total, se ha incurrido en un incumplimiento de menor gravedad (por ejemplo, parcial o defectuoso). Bien entendido: no es que la modificación se produce porque así se lo ha estipulado explícitamente, sino partiendo del sentido y alcance de la propia cláusula penal. En otros términos: interpretándola en profundidad, como corresponde.

El caso típico -y muy difundido, incluso entre las legislaciones restrictivas del siglo XIX- es el de la reducción de la pena en proporción al cumplimiento parcial de la obligación principal aceptado por el acreedor. Por ejemplo, la obligación se cumple por la mitad y la pena se reduce en la misma proporción.

Es el sistema que había adoptado el Código Civil de Vélez, que solo admitía esta excepción a la regla general.

2.b) Sistema que admite la modificación de la pena abusiva

En este caso, a diferencia del anterior, la modificación se basa en que la cláusula penal presenta alguna patología (por ejemplo, es excesiva o insuficiente).

En la práctica, las legislaciones que admiten la modificación de la pena abusiva (2.b) también lo hacen en virtud de la causal prevista en (2.a). Es nuestro caso, sin ir más lejos.

Agrego tres subclasificaciones del sistema que admite la modificación de la pena abusiva:

2.b.i) Sistema que solo admite reducción de la pena y sistema que también admite su aumento

El primero solo ataca a la cláusula penal excesiva, imponiendo o habilitando su reducción. Es el caso del Codice Civile italiano de 1942 (artículo 1384) y del Código Civil de Jordania (artículo 364), entre otros.

En el segundo sistema, en cambio, es posible tanto reducir la pena excesiva como aumentar la insuficiente (en rigor, respecto a esto último, no se aumenta 
la pena: se impide que opere como techo resarcitorio, de modo que el acreedor tiene derecho a que se le indemnicen los daños que la pena no llega a compensar). Es el caso del BGB (artículos 340.2 y 343$)^{7}$ y del Código Civil de Francia tras las modificaciones legislativas de 1975 y 1985 (artículos 1152 y 1231).

El régimen argentino de la cláusula penal solo prevé la reducción de la pena abusiva. Sin embargo, interpretado de manera sistemática, también resuelve el problema de la pena insuficiente, habilitando al acreedor a reclamar el daño no cubierto, al menos en los casos patológicos o más extremos.

\section{2.b.ii) Sistema rígido y sistema flexible}

En el sistema rígido, el legislador tasa de antemano cuál es la desproporción que habilita la modificación de la pena. Es el caso de la legislación brasileña, que fija como máximo de la pena compensatoria el valor de la prestación principal (Código Civil, artículo 412), como así también el de la boliviana (Código Civil, artículo 534) y la portuguesa (Código Civil, artículo 811.3 [la pena no puede exceder el valor del perjuicio causado por el incumplimiento de la obligación principal]). También el del Código Civil de Chile, cuyo artículo 544 prohíbe que el valor de la pena compensatoria exceda el doble del valor de la prestación principal.

En el sistema flexible, el legislador, en vez de tasar de antemano la desproporción que habilita para modificar la pena, establece parámetros abiertos y elásticos, cuya concreción les corresponde a los jueces. Es el seguido mayoritariamente. Por ejemplo, por nuestro ordenamiento, que habilita la reducción de las penas "cuando su monto [es] desproporcionado con la gravedad de la falta que sancionan, habida cuenta del valor de las prestaciones y demás circunstancias del caso" (artículo 794, segundo párrafo, del CC).

No obstante, las diferencias que estos sistemas presentan entre sí comparten un concepto central: que la cláusula penal típica -la punitiva- es válida. Esto es, que cabe estipular una penalidad para el incumplidor, una sanción o consecuencia jurídica más grave que la que tendría que afrontar si incumpliese la obligación y se le aplicasen las reglas generales. De hecho, es la cláusula penal típica que el legislador presupone cuando regula esta figura. Va de suyo, entonces, que la pena puede ser de mayor entidad que la prestación principal. Por ejemplo, si las dos son dinerarias, lo normal es que la pena consista en una suma mayor. En

7 En realidad, no es que se puede modificar la cláusula penal que no alcanza para cubrir todo el daño causado: la regla general es que la pena estipulada es solo un mínimo, al que el acreedor puede sumar el resarcimiento del daño no compensado por la pena. Así está previsto en el § 340.2. 
todo caso, estos sistemas coinciden en que la pena no se puede reducir si, aun siendo desproporcionada, la proporción no es excesiva o intolerable.

Como hemos visto, en el derecho anglosajón se adopta un abordaje muy distinto. Se distingue entre las cláusulas de liquidación de daños (liquidated damages clauses), que son válidas, y las penas (penalties), que no lo son. La posibilidad del exceso se extirpa de cuajo: no se trata de moderar la pena: lisa y llanamente es inválida.

2.b.iii) Sistema que requiere la explotación del estado de inferioridad del deudor por parte del acreedor y sistema que solo requiere la desproporción objetiva De acuerdo con el primer sistema, la pena solo se reduce si, además de ser desproporcionada con el valor del daño causado por el incumplimiento, ha sido estipulada porque el acreedor se aprovechó de la situación de inferioridad del deudor. Según este enfoque, entonces, la pena abusiva es una especie de lesión objetiva-subjetiva.

Conforme al segundo sistema, en cambio, para la reducción de la pena basta con que sea desproporcionada objetivamente con el daño o la prestación principal.

El primer sistema es el adoptado en la actualidad por la mayoría de los países que pertenecen al sistema continental europeo, con unas pocas y cada vez más raras excepciones. El segundo es menos frecuente. Por ejemplo, ha sido adoptado por los Principios UNIDROIT sobre los contratos comerciales internacionales, de 2016, tanto para la lesión en general como para la cláusula penal en particular, que están reguladas en clave objetiva. De todos modos, si nos despegamos de un análisis demasiado formal, también habría que sumar a este segundo sistema a muchos ordenamientos jurídicos que, más allá de lo que dicen sus leyes, de hecho operan en clave objetiva. ${ }^{8}$

¿Cómo estamos en nuestro país? Formalmente, para reducir la pena se requieren tanto la desproporción como la explotación por parte del acreedor del estado de inferioridad del deudor. Es lo que establece el CC en la regulación específica de la cláusula penal abusiva (artículo 794, párrafo segundo) y lo que resulta del régimen genérico de la lesión (artículo 332). Sin embargo, en la práctica, las reglas se aplican en clave puramente objetiva.

Cierro con dos aclaraciones respecto a esta última clasificación:

- Lo dicho vale respecto a la cláusula penal en general, pero no para aquella que accede a un contrato de consumo o celebrado por adhesión a cláusulas

8 Véanse, por ejemplo, los proyectos de armonización del derecho europeo de los contratos que regulan la lesión subjetiva. 
generales predispuestas cuyo deudor es el consumidor o adherente. El mero hecho de asumir alguno de estos dos roles constituye, por sí, una situación de inferioridad. No se precisa, además, la necesidad, debilidad síquica o inexperiencia requerida en el régimen general. Es decir que basta el desequilibrio objetivo. Es más, en algunos ordenamientos, ni siquiera se requiere esto último: la cláusula penal es extirpada per se.

- En el sistema anglosajón, la cláusula -salvo que sea estipulada para anticipar el daño resarcible que se puede prever al convenirla- es inválida. En otros términos: la cláusula penal punitiva (la penalty clause) no es válida, sí la cláusula de liquidación de daños (liquidated damages clause). Es cierto que el elemento subjetivo tiene relevancia (mayor en el sistema inglés, menor en el estadounidense). Pero en un sentido distinto: si la cláusula se pacta para compensar el daño que se derivará del eventual incumplimiento, es una liquidated damages clause, mientras que es una penalty si se la estipula para penalizar o castigar al incumplidor. En cualquier caso, no se hace referencia a la explotación de una situación de inferioridad, que es lo que aquí estamos considerando para distinguir estos dos sistemas.

\subsection{Derecho argentino: visión panorámica}

\subsubsection{Regla general}

La cláusula penal punitiva o coercitiva es válida. Es decir, la que -bien sea porque es acumulable o por su entidad-coloca al incumplidor en una situación más gravosa que la que resultaría de la aplicación de las reglas generales. De hecho, es la pena típica presupuesta por el legislador. Obviamente, también es válida la que constituye una simple estimación anticipada de los daños. Seguimos, entonces, la línea del derecho continental europeo.

La regla general es que la cláusula penal es inmutable. Así resulta de varios artículos del CC:

Relación con la indemnización. La pena o multa impuesta en la obligación suple la indemnización de los daños cuando el deudor se constituyó en mora; y el acreedor no tiene derecho a otra indemnización, aunque pruebe que la pena no es reparación suficiente. (Artículo 793 del CC)

Ejecución. Para pedir la pena, el acreedor no está obligado a probar que ha sufrido perjuicios, ni el deudor puede eximirse de satisfacerla, acreditando que el acreedor no sufrió perjuicio alguno. (Artículo 794 del CC) 
Me refiero, queda claro, a que la cláusula es inmodificable sin la voluntad de quienes la estipularon. Esta es la regla general.

La inmutabilidad opera en los dos sentidos:

- la pena no se puede reducir aunque sea excesiva;

- tampoco se la puede aumentar aunque sea insuficiente: opera como límite de lo que puede reclamar el acreedor.

\subsubsection{Excepciones}

La regla general admite varias excepciones. Bosquejo una síntesis:

1) Cláusula penal excesiva

1.a) Contratos de consumo o celebrados por adhesión

La cláusula es inválida si el deudor es el consumidor o adherente.

\section{1.b) Demás contratos}

1.b.i) Cumplimiento parcial, defectuoso o inexacto

La pena debe reducirse proporcionalmente si, aun siendo aplicable, se verifica un incumplimiento de menor entidad que aquel para el cual fue realmente prevista. Por ejemplo, si se produce un incumplimiento parcial y la pena, en el fondo, fue estipulada para que se pagase en su integridad solo ante un incumplimiento total.

\section{1.b.ii) Pena abusiva}

La pena debe reducirse. En principio, la ley supedita la reducción a que se verifiquen dos requisitos: la desproporción (elemento objetivo) y el abusivo aprovechamiento de la situación de inferioridad del deudor por parte del acreedor (elemento subjetivo). De todos modos, el segundo de estos requisitos no se aplica en la práctica. En cuanto al primero, la desproporción debe ser importante, no basta cualquier desajuste. ¿En qué medida? La ley no lo tasa en abstracto. La cuestión debe dilucidarse en cada caso, aplicando estándares abiertos y flexibles.

2) Cláusula penal insuficiente

2.a) Contratos de consumo o celebrados por adhesión

La cláusula es inválida si el acreedor es el consumidor, usuario o adherente. 


\section{2.b) Demás contratos}

La cláusula es válida, en principio. Por excepción, y no obstante lo estipulado, el acreedor tiene derecho a que se le resarza el daño no cubierto por la pena en dos casos:

- si el deudor incumple con dolo o culpa grave;

- si la pena es ostensiblemente inferior al daño causado por el incumplimiento.

\section{La desproporción}

\subsection{Introducción}

De acuerdo con el artículo 794 del CC,

[1] os jueces pueden reducir las penas cuando su monto desproporcionado con la gravedad de la falta que sancionan, habida cuenta del valor de las prestaciones y demás circunstancias del caso, configuran un abusivo aprovechamiento de la situación del deudor. ${ }^{9}$

Dos son, entonces, los requisitos que la ley exige:

1) Elemento objetivo: la desproporción de la pena.

2) Elemento subjetivo: el aprovechamiento abusivo de la situación (de inferioridad) del deudor. A su vez, este segundo elemento puede descomponerse en dos: el aprovechamiento y la situación de inferioridad.

Esto es lo que dice la ley. De todos modos, en la práctica, la reducción de la pena se basa en factores puramente objetivos. Abierta o encubiertamente, este es el criterio que en realidad aplican los tribunales. Si no en todos los casos, al menos sí en la mayoría.

A continuación, analizaré el primero de estos requisitos.

\subsection{Consideraciones generales}

Estamos ante un concepto relativo: no hay penas excesivas en términos absolutos. Depende de su entidad, ciertamente, pero puesta en relación con la gravedad de la falta que se sanciona (por ahora, digámoslo así). Esto quiere decir que una misma pena podría ser desproporcionada en determinado contexto y no en otro. Por ejemplo, una pena compensatoria de 1 millón de pesos podría ser proporcionada si el valor de la prestación principal fuese de 800 mil pesos y desproporcionada si fuese de 150 mil pesos.

9 Énfasis agregado. 


\subsection{La desproporción debe ser evidente. El impacto de la función compulsiva de la pena}

Para que la pena sea reducible, el artículo 794 solo requiere que sea desproporcionada. Sin embargo, el artículo 332, al regular la lesión en general, exige, además, que la desproporción sea evidente. Es decir, reclama un plus. ¿Es esto aplicable a la cláusula penal? Entiendo que sí por dos razones:

1) La igualdad de tratamiento con los demás casos de lesión

No hay ninguna razón por la cual se deba tener una menor tolerancia con el acreedor de una cláusula penal que la que se le tiene a cualquier contratante desde el régimen de la lesión en general. En otros términos: no hay por qué admitir desde el régimen genérico de la lesión que las prestaciones sean desproporcionadas, siempre que la desproporción no sea evidente o importante, y no admitirlo, en cambio, respecto a las cláusulas penales. Es más, hay todavía más razones para hacerlo, lo que me lleva al punto que sigue.

\section{2) La función compulsiva de la pena}

En su versión típica, la pena cumple una función compulsiva; función que nuestro ordenamiento valida y respalda, pero que quedaría borrada si el valor de la prestación o del resarcimiento de referencia representase el límite del valor de la pena. Por esta razón, debe tolerarse que esta tenga un plus por encima de esos valores, de modo que pueda cumplir su función. ${ }^{10}$ Es lo normal, lo típico en una cláusula penal. ${ }^{11}$ Como gráficamente se ha señalado, "[l]a pena exorbitante o excesiva, no es aquella que importe cualquier exceso por sobre la indemnización plena, sino que por 'pena excesiva' debe entenderse la que es excesiva 'como pena”' (Tale, 2009, § III).

10 Véanse Tale (2009, § II y III); Ossola y Lorenzetti (2015, p. 235); Cámara Nacional de Apelaciones en lo Civil, sala I, D., A. J. c/D., M. A. s/ejecución de convenio; Cámara Nacional de Apelaciones en lo Civil, sala J, Celico, Pascual Leandro Hipólito c/Triex SA s/daños y perjuicios; Cámara 2a de Apelaciones en lo Civil, Comercial, Minas, de Paz y Tributaria de Mendoza, Sucesores de Resa, Domingo c/Bommecino María Esther y Ots. s/ejec. típica; Cámara de Apelaciones de Esquel, P., O. A. c/B., L. y otro s/resolución de contrato s/daños y perjuicios; Cámara Nacional de Apelaciones en lo Civil, sala M, Zucchini de Morra, Josefina c/Quinteros, Miguel y otro s/ejecución de alquileres; Cámara Nacional de Apelaciones en lo Civil, sala A, Damonte, Carlos H. c/García, Mabel S. y otros.

11 Vease Cámara de Apelaciones de Esquel, P., O. A. c/B., L. y otro s/resolución de contrato s/daños y perjuicios ("Siempre ha de tratarse de una suma mayor a la que hubiera correspondido por resarcimiento, caso contrario carecería de sentido incluirla. Dicho de otra forma: la cláusula penal, por naturaleza implica una mejora económica para quien la cobra o pretende cobrarla y es que si no fuera así, carecería de sentido incluirla en un contrato. Si el cobro de la cláusula penal no implicase una mejora económica para quien la percibe, no sería cláusula penal ni tendría posibilidad alguna de constreñir el cumplimiento"). 
Así las cosas, hay que distinguir tres situaciones:

1) No hay desproporción. No cabe reducir la pena.

2) Hay desproporción. En este caso, hay que distinguir, a su vez, dos supuestos:

2.a) La desproporción no es evidente. Tampoco cabe reducir la pena.

2.b) La desproporción es evidente. La pena es reducible si concurren los demás requisitos legales.

Lo expuesto amerita algunas aclaraciones:

1) El tema no pasa tanto por si la desproporción es o no evidente, sino por si es importante. Uso este término ("evidente") porque así lo hace el artículo 332 y también lo hacía el artículo 954 del viejo CC, razón por la cual se ha difundido en la doctrina y en la jurisprudencia.

Por supuesto, a la desproporción hay que probarla, pero no es preciso que sea evidente. En algunos casos, lo será, en otros no. Lo que cuenta no es si la desproporción es o no fácilmente perceptible, sino su entidad. La desproporción no es más o menos importante por el hecho de ser más o menos visible o perceptible, de lo contrario, habría que concluir que solo pueden reducirse las penas cuya desproporción pueda determinarse con facilidad, lo que no tendría sentido ni sería congruente con la finalidad ni el fundamento de la lesión, ni tampoco con su historia.

2) En teoría, no basta la desproporción evidente para que se deba reducir la pena: esto es condición necesaria, pero no suficiente. Aquí me he limitado a encuadrar el tema teniendo en cuenta solo esta dimensión -la objetiva- del problema. Se supone que, además, es preciso que concurra un segundo elemento -el subjetivo-: el aprovechamiento abusivo por parte del acreedor de la situación de inferioridad del deudor. Cuestión distinta es la de si el sistema funciona así en la práctica.

En cualquier caso, lo que queda claro es que hay un punto de corte hasta el cual la desproporción es tolerable y a partir del cual deja de serlo. Ahora bien, ¿cuál es este punto? La respuesta tiene varias dimensiones, que analizaré en los parágrafos que siguen.

\subsection{Elementos entre los cuales debe existir la desproporción \\ 4.4.1. Introducción}

Para que la pena sea reducible, debe haber desproporción, pero ¿entre qué? Repasemos lo que el artículo 794 del Código Civil y Comercial dispone al respecto: 
Los jueces pueden reducir las penas cuando su monto desproporcionado con la gravedad de la falta que sancionan, habida cuenta del valor de las prestaciones y demás circunstancias del caso, configuran un abusivo aprovechamiento de la situación del deudor. ${ }^{12}$

Por lo tanto, según la ley, el cotejo debería efectuarse entre

1) la pena, $y$

2) la gravedad de la falta, teniendo en cuenta el valor de las prestaciones y las demás circunstancias del caso.

Lo primero está muy claro, lo segundo no tanto.

\subsubsection{Primer factor: la pena}

Al ponderar si la pena es excesiva, no solo debe tenerse en cuenta su entidad, sino también cualquier otra característica que pueda ser relevante en este aspecto. Destaco dos:

1) ¿Es una pena moratoria, compensatoria, por resolución o resarcitoria del cumplimiento parcial, defectuoso o inexacto? Por ejemplo, una pena que podría ser un disparate como moratoria podría no serlo como compensatoria. Supongamos que, en una economía no inflacionaria, se fija una pena de 1100000 pesos para el incumplimiento de una obligación cuya prestación tiene un valor de 1 millón de pesos. En la medida en la que cabe hacer una ponderación en abstracto, este monto sería razonable si la pena fuese compensatoria, pero no si fuese moratoria y se aplicase por un retraso de unos pocos días.

2) ¿Es una pena acumulable? Una pena no acumulable de cierto valor podría ser proporcionada y no serlo si fuese acumulable.

\subsubsection{Segundo factor: ¿la gravedad de la falta? \\ 4.4.3.1. Consideraciones generales}

En cuanto al segundo factor -aquello con lo cual la pena se coteja para determinar si es o no proporcionada-, la gravedad de la falta ocupa un lugar protagónico, al menos en la letra del artículo 794. Un lugar excesivo, en la mayoría de los casos. De todos modos, como la fórmula legal es abierta ("las demás circunstancias del caso"), este inconveniente puede superarse.

En rigor, la gravedad de la falta es el único elemento que se menciona, y el valor de las prestaciones y las demás circunstancias del caso son factores auxilia-

12 Énfasis agregado. 
res para ponderarla, pero, como es obvio que con la gravedad no alcanza para efectuar de manera cabal esta ponderación, la doctrina y la jurisprudencia le han buscado la vuelta para abrir el juego e incluir otros factores. En especial, el daño sufrido por el acreedor a raíz del incumplimiento de la obligación principal. Esto se ha logrado, por lo general, a través de una de estas dos vías:

- interpretando con amplitud lo que sería la gravedad de la falta, o

- abriendo explícitamente el juego al admitir otros factores junto con el anterior.

Cualquiera de los dos caminos es aceptable. Por mi parte, me decanto por el segundo al mero efecto de resaltar la importancia del factor-perjuicio, ya que, como veremos, suele ser el que más gravita a la hora de determinar si hay o no desproporción. De todos modos, esta diferencia en el encuadre teórico no tiene ninguna repercusión práctica.

Analicemos, entonces, los factores que deben ponderarse para determinar este segundo polo del cotejo.

\subsubsection{La gravedad de la falta}

¿En qué consiste este factor? Como lo anticipé, hay dos líneas interpretativas:

1) Para algunos, se hace referencia al grado de reproche que merece el deudor que ha incumplido. Cuanto más reprochable, más grave, y viceversa.

2) Para otros, se alude principalmente al perjuicio sufrido por el acreedor. Cuanto mayor sea el perjuicio, mayor, también, la gravedad de la falta, y viceversa. Por lo general, quienes participan de esta tesis consideran que el factor-perjuicio no está enumerado en la ley y, viendo que es indispensable, lo introducen de este modo indirecto.

Según el Diccionario de la lengua española, "gravedad", en su primera acepción, significa "cualidad de grave", y el adjetivo "grave", en su segunda acepción, significa que algo es "grande, de mucha entidad o importancia" (Real Academia Española, 2014). Por lo tanto, la ley alude a una falta importante, de mucha entidad. Además del perjuicio (que analizo por separado), la cuestión depende, entre otros factores, de los siguientes:

\section{1) Imputabilidad}

El deudor ¿actuó con dolo, con culpa o se lo imputó objetivamente? Se discute si el incumplimiento debe ser imputable para que la pena sea exigible. Aquí me limito a recordar que, aunque el panorama no es claro, se aplican, en definitiva, 
las reglas sobre la imputabilidad del régimen general de la responsabilidad civil. Por ende, según el supuesto de que se trate, puede que la responsabilidad sea objetiva o subjetiva. Esto implica que en ciertos casos (aquellos en los que el factor de atribución es objetivo) el deudor deberá la pena aun cuando no haya actuado con culpa o dolo, mientras que en otros se requerirá su reprochabilidad subjetiva.

En lo que aquí nos concierne, la gravedad de la falta es mayor si el deudor actuó con dolo, menor si lo hizo con culpa y todavía menor si se lo imputó objetivamente. ${ }^{13}$ Si bien su no culpa no lo liberará de la pena en este último caso (por fuerza, la responsabilidad será objetiva; de lo contrario, ni tendría sentido ponderar si la pena es o no abusiva, ya que no sería exigible), sí podrá gravitar a favor de que se la reduzca.

\section{2) Incumplimientos anteriores del deudor}

Si el deudor ya ha incumplido anteriormente, bien sea la obligación a la que accede la pena u otra conexa, la gravedad de la falta es mayor, y viceversa.

3) Menosprecio de los derechos del acreedor

A mayor menosprecio, mayor gravedad de la falta, y viceversa.

4) Conducta adoptada para minimizar los efectos del incumplimiento Si el deudor no procuró minimizarlos, su gravedad es mayor, y viceversa. Por ejemplo, el preaviso del incumplimiento realizado de buena fe podría considerarse un factor que atenúe la gravedad de la falta (v. gr., si el deudor anuncia con la máxima antelación posible que por falta de insumos no podrá entregar en término la prestación prometida).

5) Probabilidad de que el deudor incurra en nuevos incumplimientos Este factor se alinea con la función preventiva y coercitiva de la cláusula penal. Si bien la cuestión no puede reducirse a un análisis puramente económico, hay que tomar en cuenta en qué medida la eventual reducción de la pena puede incentivar el incumplimiento, o al menos resentir o neutralizar la eficacia compulsiva de la cláusula.

La conducta anterior del deudor puede ser un indicador relevante para efectuar este pronóstico (aunque no el único, desde luego).

13 Por esta razón, los tribunales suelen rechazar el pedido de reducción de la pena cuando el incumplimiento de la obligación principal fue doloso. Véase, en este sentido: Cámara Nacional de Apelaciones en lo Civil, sala B, Cebrian Inmobiliaria SA c/Cebrian Hermanos SA s/cobro de sumas de dinero. 
Muchos de estos factores tienden a superponerse o al menos a implicarse recíprocamente. Por ejemplo, quien incumple con dolo o no adopta medidas para minimizar los efectos del incumplimiento revela cierto menosprecio de los derechos del deudor.

\subsubsection{El daño}

Otro factor relevante es el daño sufrido por el acreedor a raíz del incumplimiento de la obligación principal. ${ }^{14} \mathrm{El}$ más relevante, a mi entender, cuando la pena sustituye al resarcimiento legal de ese daño. Situación que se presenta con estas penas:

- La pena moratoria, que sustituye al resarcimiento legal del daño moratorio.

- La pena por resolución, que sustituye al resarcimiento legal del daño derivado del incumplimiento y la subsiguiente resolución.

- La pena estipulada para el cumplimento parcial, defectuoso o inexacto, que sustituye al resarcimiento legal del daño derivado de este tipo de incumplimientos.

Naturalmente, al ponderar este factor, se debe incluir tanto el daño patrimonial como el extrapatrimonial: cualquier interés legítimo que la prestación principal estuviese encaminada a satisfacer. ${ }^{15}$ Por ejemplo, a la hora de denegar el pedido de reducción de la pena en un caso ventilado ante nuestros tribunales, se tuvo en cuenta, entre otros factores, la frustración del proyecto familiar del comprador (quien, varios años después de haber firmado un boleto, resolvió el contrato porque el vendedor no había cumplido su obligación de escriturar). ${ }^{16}$

Refiero un caso que muestra a las claras la importancia de este factor: ${ }^{17}$

- Se celebró una compraventa que incluía una cláusula penal.

- El vendedor incurrió en mora en la obligación principal (la obligación de escriturar).

- El tribunal de primera instancia le aplicó la pena moratoria pactada. Como

14 Es, por lejos, el más tenido en cuenta por la jurisprudencia cuando se trata de una pena sustitutiva de algún tipo de resarcimiento. Véase, por ejemplo, Cámara Nacional de Apelaciones en lo Civil, sala H, Rant Pazos, Pablo Ricardo c/Compañia Panamericana del Oeste SA s/daños y perjuicios; Cámara Nacional de Apelaciones en lo Civil, sala F, Bulo, R. v. Comisión Municipal de la Vivienda.

15 Véanse Kemelmajer de Carlucci (1981, p. 112); Kemelmajer de Carlucci y Bueres (1998, p. 560); Larenz (1959, p. 234); Llambías (1983, p. 447); Piris (2015, p. 59).

16 Véase Cámara Nacional de Apelaciones en lo Civil, sala A, R., F. L. c/Manelma S. A. y otros s/daños y perjuicios.

17 Véase Cámara Nacional de Apelaciones en lo Civil, sala F, Bulo, R. v. Comisión Municipal de la Vivienda. 
había inflación, actualizó la pena con los índices oficiales (práctica que entonces se admitía).

- El vendedor apeló.

- El tribunal de alzada revocó la sentencia, reduciendo la pena a una décima parte del monto que se había fijado en la instancia anterior. Refiero las razones principales en las que se fundó:

1) Sería un absurdo jurídico que la vendedora tuviese que transferir el dominio del inmueble y además abonar al comprador una suma varias veces superior al precio pactado.

2) A pesar de la mora del vendedor en la obligación de escriturar, la compradora ya tenía el bien en su poder.

3) La compradora pudo acceder al inmueble bajo condiciones muy ventajosas gracias al plan de pagos acordado en el contrato.

Por estas razones, el tribunal consideró que si bien el vendedor debía pagar la pena, había que reducirla a un décimo de su valor. ${ }^{18}$ En definitiva, lo que hizo fue ponderar el valor de la pena con el valor del daño que el comprador había sufrido por el incumplimiento de la obligación principal, daño que fue mucho menor porque tuvo la posesión del inmueble vendido. ${ }^{19}$

Refiero un segundo caso, esta vez referido a una pena por resolución, en el cual el factor-perjuicio también fue decisivo: ${ }^{20}$

- Se celebró una compraventa inmobiliaria el 12 de noviembre de 1984.

- La compradora pagó el 50\% del precio.

- El contrato incluía una cláusula penal por resolución por la cual el vendedor tenía derecho a retener lo pagado como precio si el comprador no pagaba el saldo el 19 de noviembre, fecha convenida para la escrituración y entrega de la posesión.

18 Se aplicó el artículo 656, segundo párrafo, del CC (que, como vimos, es similar al artículo 794, segundo párrafo, del CC).

19 En el mismo sentido, véase Cámara Nacional de Apelaciones en lo Civil, sala K, Coppola Libetta, Marco Fabio c/Oliva, Donald s/escrituración ordinario (también se tuvo en cuenta que el comprador lacreedor de la pena] solo había pagado algo más del $20 \%$ del precio, ya que debía abonar el saldo recién al momento de la escrituración, que se demoró por culpa del vendedor [y por lo cual este último debió pagar la pena]); Cámara Nacional de Apelaciones en lo Civil, sala G, García Orosco, Benito c/Ollantay, S.A.; Papa (2016) (la aplicación del criterio es mucho más discutible en este caso, habida cuenta de que se habían previsto sendas penas moratorias para las obligaciones de entregar la posesión y escriturar y se redujo la prevista para esta última invocando el cumplimiento de la otra; discrepo con el tribunal: la previsión de penas diferenciadas pone en evidencia que para fijar una [la accesoria de la obligación de escriturar] fue indiferente el eventual cumplimiento de la garantizada por la otra [la de entregar la posesión del inmueble]).

20 Véase Cámara Nacional de Apelaciones en lo Civil, sala C, Maidana de Pis, Aurora F. c/Forlenza, Francisco L. 
- El plazo convenido se prorrogó por dos días -hasta el 21 de noviembre- porque la compradora no logró reunir los fondos necesarios para pagar el saldo.

- Como la situación persistía para el 21 (la compradora confió en que entre sus familiares y amigos le prestarían el capital, pero la ilusión no se concretó), la vendedora ejerció la facultad resolutoria. Ese mismo día, las partes celebraron un acuerdo extintivo por el cual, ante la propuesta de la vendedora, se convino la "rescisión" de la operación "aplicando las penalidades pactadas". Esto es, la compradora se avino a perder, como pena por resolución, el importe que ya había entregado a cuenta de precio.

- Tiempo después, demandó a la vendedora. Solicitó la reducción de la pena por abusiva y la restitución de lo pagado en exceso.

- El tribunal hizo lugar a la demanda. Redujo la pena en un 60\%, que así pasó de un $50 \%$ a un $20 \%$ del precio acordado para la compraventa.

- Para resolver cómo lo hizo, el tribunal consideró que concurrían todos los elementos de la lesión: la desproporción de la pena, la situación de inferioridad de la víctima (en concreto, necesidad e inexperiencia) y el aprovechamiento abusivo por parte del acreedor-vendedor. ${ }^{21}$

- En cuanto al elemento objetivo, destacó que entre la celebración del contrato y la fecha de la resolución solo habían transcurrido nueve días y que, además, la compradora nunca tuvo la posesión del inmueble. "No cabe imaginar daños de esa naturaleza para la frustración del contrato en tan breve tiempo", observó.

Obviamente, el factor-daño gravita más cuando, como es lo usual, la cláusula penal cumple una función resarcitoria. No obstante, y aunque en menor medida, también pesa cuando la pena cumple una función puramente compulsiva (como ocurre cuando es acumulable con el resarcimiento legal). Por ejemplo, no es lo mismo una pena acumulable que representa un 50\% de este resarcimiento que la que lo centuplica.

21 En cuanto a la necesidad, el tribunal destacó que la compradora contaba con "limitadas posibilidades económicas frente a una acuciante necesidad de adquirir vivienda por los altos alquileres de plaza"; que era "encargada de costura del Sanatorio Anchorena, con modestos ingresos" y estaba casada "con el señor Pis, de oficio lavacopas" y que "[h]icieron ingentes esfuerzos por adquirir vivienda propia y para sus dos hijos menores, mediante ahorros y préstamos de personas amigas".

En cuanto a la inexperiencia, además de apoyarse, en parte, en lo anterior, el tribunal hizo hincapié en la "escasa instrucción de la actora y su marido". 


\subsubsection{Valor de la prestación principal}

Sin duda, el valor de la prestación principal -elemento mencionado en el artículo 798- desempeña un rol de particular relevancia a los efectos de dilucidar el perjuicio sufrido por el acreedor. Pero su incidencia difiere, y mucho, en función del tipo de pena de que se trate.

Es el factor más relevante en el caso de la cláusula penal compensatoria no acumulable (esto es, la compensatoria típica), ya que aquí la pena sustituye a la prestación principal (y al resarcimiento del daño causado por su incumplimiento). Naturalmente, esto no implica que la pena deba tener el mismo valor que esa prestación, pero sí que este valor será el punto de referencia ineludible para determinar si la pena es o no excesiva. No es lo mismo, por ejemplo, si la pena vale un $30 \%$ más que la prestación principal que si la excede en un 1000\%.

La incidencia de este factor es menor, en cambio, cuando la pena no sustituye a la obligación principal, sino al resarcimiento del daño producido por su incumplimiento, como es el caso de las demás cláusulas penales. En este tipo de supuestos, el valor de la prestación principal gravita de modo indirecto, ya que el perjuicio sufrido por el acreedor (que es el factor más relevante para el análisis en estos casos, como vimos) depende, entre otros factores, del valor de esa prestación. Pensemos, por ejemplo, en una pena moratoria. Para determinar si es o no excesiva, habrá que cotejarla con el resarcimiento legal del daño moratorio, y la entidad de este daño depende, en gran medida, del valor de la prestación objeto de la obligación incumplida. Con las adaptaciones correspondientes, lo mismo vale para la pena por resolución y la resarcitoria de otros incumplimientos relativos.

Nuestra ley no tasa el grado de desproporción que hace reducible la pena. El tema queda librado a la apreciación de los jueces, aunque al hacerlo deben aplicar el criterio que está contenido en la ley.

Nos desmarcamos, así, de los sistemas legales que tasan la desproporción. Entre estos, el valor de la prestación principal es el parámetro que suele tomarse como referencia, sobre todo en relación con la pena compensatoria no acumulable (aunque esto último no suele explicitarse, por cierto). Por ejemplo, el Código Civil de México dispone que "[l]a cláusula penal no puede exceder ni en valor ni en cuantía a la obligación principal” (artículo 1843). Esta disposición es doblemente criticable: al problema que de por sí implica la tasación legal predeterminada se le agrega que el criterio escogido es, a todas luces, insuficiente: en cierto sentido, al deudor le conviene más tener que pagar una pena (sujeta a este límite máximo) que resarcir de acuerdo con el derecho común el daño causado por el incumplimiento, ya que, en este segundo caso, además de 
pagar la prestación principal, bien sea en especie o por equivalente, debería indemnizar al acreedor. Por esta razón, las leyes que tasan el límite de la pena suelen establecer un parámetro más permisivo que el que acabo de referir. Por ejemplo, fijando el tope en el duplo del valor de la prestación principal. ${ }^{22}$

En este tipo de sistemas, el valor de la prestación también se ha tomado como referencia cuando la pena compensatoria es acumulable con la prestación principal. Por ejemplo, el artículo 712 del Código Civil de Costa Rica establece lo siguiente:

Cuando sólo se reclame la pena, ésta no puede exceder el valor ni en cuantía a la obligación principal, y en los casos en que es posible el reclamo del principal y de la pena conjuntamente, la pena no puede exceder de la cuarta parte de aquél.

Si bien la primera parte de la norma alude a la pena compensatoria no acumulable, que sería la tradicional, a continuación se prevé el caso en el que sí lo es, y el límite, lógicamente, no se fija en el valor de la prestación, sino en una parte proporcional (en este caso, un 25\%).

De todos modos, incluso en el caso de la pena compensatoria, no basta con cotejarla con el valor de la prestación principal, ya que no solo sustituye a esta última, sino también al resarcimiento legal del daño compensatorio causado por el incumplimiento. Por lo tanto, hay que ponderar, asimismo, el valor de este daño, que no depende solo del valor de la prestación incumplida. De hecho, es perfectamente posible que de dos prestaciones de un mismo valor, una justifique una pena de cierta entidad y la otra no. Por ejemplo, no es lo mismo si debe entregarse una máquina cuya privación causa al acreedor un lucro cesante enorme porque paraliza su planta industrial que si hay que entregar un inmueble para su uso en tiempo de vacaciones. El impacto es muy distinto en uno y otro caso, por más que el valor de las prestaciones sea el mismo.

\subsubsection{Otros factores}

Los factores precedentes son, cada uno en su ámbito, los más relevantes. Pero no son los únicos, sobre todo cuando la pena cumple una función más puni-

22 Por ejemplo, el Código Civil de Colombia (artículo 1601), el Código Civil de Chile (artículo 1504, que contiene la misma salvedad que el colombiano) y el Código Civil de El Salvador (artículo 1415). En el caso de Colombia y de Chile, se agrega que la regla no se aplica al mutuo ni a las obligaciones de valor inapreciable o indeterminado; en el de El Salvador, lo mismo, pero solo con relación a estas últimas. 
tiva que resarcitoria. Sin ánimo taxativo, agrego los siguientes, cuyo peso es muy dispar:

1) Eventuales ventajas que el incumplimiento le ha reportado al deudor ${ }^{23}$

Una de las funciones de la cláusula penal es prevenir y desincentivar el incumplimiento de la obligación principal, alterando la ecuación costo-beneficio del deudor al imponerle un costo adicional a través de la pena, de modo que para él no "sea negocio" incumplir. Por lo tanto, no se puede reducirla cuando esto implique privarla de eficacia en este aspecto.

Por cierto, no es necesario que el deudor se haya beneficiado económicamente con su incumplimiento para que se le aplique la pena. Pero, en caso de que este beneficio exista -como es lo usual-, hay que incluirlo en el análisis, en el sentido apuntado.

2) Situación económica de las partes ${ }^{24}$

Si bien no creo que a este factor se le deba asignar un peso decisivo, hay que tenerlo en cuenta, sobre todo cuando la cláusula penal cumple una función coercitiva o sancionatoria. Una misma pena puede ser insignificante para un deudor y abrumadora para otro.

3) Otras sanciones aplicables al deudor ${ }^{25}$

De ser también aplicables otras sanciones, hay que ponderarlas para que su impacto conjunto sea excesivo. Al respecto, el artículo 1714 del CC dispone lo siguiente:

Punición excesiva. Si la aplicación de condenaciones pecuniarias administrativas, penales o civiles respecto de un hecho provoca una punición irrazonable o excesiva, el juez debe computarla a los fines de fijar prudencialmente su monto.

4) Las demás circunstancias del caso

El artículo 794 dispone que, al definir la cuestión, los jueces deben tener en cuenta "las demás circunstancias del caso", lo que si bien no deja de ser una obviedad (¿hay algún caso que pueda resolverse sin tener en cuenta sus circunstancias?), nos recuerda que deben ponderarse todos los factores relevantes.

23 Véanse Kemelmajer de Carlucci (1981, p. 122); Tale (2009, § II).

24 Ídem.

25 Véase Tale (2009, § II). 
Por cierto, no estamos ante un criterio adicional que viene a sumarse a los ya enumerados, más bien es una pauta genérica que tiñe, por así decirlo, todo el análisis, lo que incluye a cada uno de los criterios enumerados.

Para demostrarlo, me valdré de un caso real: un juicio por cobro de alquileres, en el cual se validó una tasa de interés moratorio del $2 \%$ diario. ${ }^{26}$ Repito: 2\% diario; $60 \%$ mensual; $730 \%$ anual (y esto suponiendo que el interés haya sido simple). No obstante, la tasa no se consideró abusiva. Y eso que se trataba de un contrato de locación y la pena pesaba sobre su parte débil, el locatario. Pero esta primera impresión cambia si tenemos en cuenta una circunstancia del caso: tuvo lugar en la década de 1980, signada por una inflación galopante. De hecho, entre otras consideraciones, el tribunal destacó que era frecuente que se estipulasen tasas superiores. Pero el punto al que quiero llegar es otro. ¿Qué criterio se utilizó para determinar si la pena era o no abusiva? Siendo moratoria, se la cotejó correctamente con el valor del perjuicio sufrido por el acreedor. Y, como era dineraria, el daño causado por la mora solo pudo valuarse teniendo en cuenta la tasa de inflación. No se trata de dos criterios distintos, insisto, sino de un único criterio (el del cotejo del valor de la pena con el del perjuicio sufrido por el acreedor), pero que solo puede aplicarse teniendo en consideración todas las circunstancias del caso.

\subsection{Libre apreciación judicial. La equidad}

La determinación de si una pena es o no excesiva queda en manos de los tribunales. Es el juez quien determina si hay desproporción, aplicando los criterios referidos (y, sobre todo, la equidad).

El microrrégimen de la reducción de la cláusula penal es compatible, en este aspecto, con el régimen general de la lesión, previsto en el artículo 332, que adopta el mismo criterio. No hemos seguido el sistema en el que en la ley se tasa de antemano la desproporción requerida para que haya lesión, cuyos referentes históricos principales son el Corpus iuris civilis (lesión enorme), el Código Civil francés (lesión enormísima) y, más recientemente, el Código Civil italiano.

La principal ventaja del sistema adoptado es que faculta al juez para resolver el conflicto con razonabilidad.

26 Véase Cámara Nacional de Apelaciones en lo Civil, sala C, Petriz, Adoración c/Casalotti, Héctor y otro. 


\subsection{Punto de corte que separa la desproporción evidente de la que no lo es: casuística}

Refiero algunos casos en los que la pena se consideró excesiva:

- En un juicio sobre un contrato de locación, cuyo alquiler mensual era de 1300 pesos, la pena por mora en el pago de los alquileres se redujo de 30 a 10 pesos diarios. ${ }^{27}$

- En otro juicio referido a una locación, se consideró abusiva una cláusula penal del $5 \%$ diario por mora en el pago de los alquileres. ${ }^{28}$ El tribunal destacó que, de aplicársela, y habida cuenta del tiempo de mora transcurrido (menos de un año), la pena equivaldría al 1800\% del canon locativo. La redujo al $7 \%$ mensual.

- En el marco de un reconocimiento de deuda y compromiso de pago, el máximo tribunal correntino consideró abusivo un interés punitorio del $365 \%$ anual. ${ }^{29}$ Tomando como referencia las tasas mensuales, destacó que la tasa activa del Banco de Corrientes ascendía al 2,12\%, que en su pico alcanzó en un trimestre el 3,78\%, y que la tasa activa del Banco Nación Argentina para operaciones de descuento de documentos comerciales era del 1,55\%.

- En una locación, el interés punitorio previsto para la mora en el pago de los alquileres se redujo del $365 \%$ anual a una vez y media la tasa activa no capitalizable del Banco Nación Argentina para operaciones ordinarias de descuentos de documentos comerciales. ${ }^{30}$

- En una compraventa inmobiliaria resuelta por incumplimiento, la pena por resolución se redujo del $66 \%$ al $33 \%$ del precio. ${ }^{31}$

- Se declaró abusiva la pena por mora en el cumplimiento de la obligación de restituir el inmueble vendido y entregado en virtud de una compraventa luego resuelta por falta de pago del saldo del precio, que se devengó por siete años y medio y ascendió a 802500 dólares. ${ }^{32}$ El inmueble se había vendido en alrededor de 274532 dólares.

27 Véase Cámara 2a en lo Civil, Comercial y Minería de San Juan, sala II, Pereira Demarchi, José Luis c/ Sancho, Francisco Javier y otros s/cobro de alquileres.

28 Véase Cámara 5a de Apelaciones en lo Civil, Comercial, Minas, de Paz y Tributaria de Mendoza, Domus Laónica Argentina S.A. y Telecom Personal S.A. s/homologación de convenio (base cont. locac.).

29 Véase Superior Tribunal de Justicia de la Provincia de Corrientes, Mutual del Personal de Agua y Energía Eléctrica de Corrientes s/concurso preventivo - inc. de revisión.

30 Véase Cámara de Apelaciones en lo Civil y Comercial de Corrientes, sala IV, Meza, Ines Ana María c/Bahle Alicia Itatí, Cubilla Félix Ariel y Bahle Carlos Daniel s/cobro de pesos (sumarísimo).

31 Véase Cámara 5a de Apelaciones en lo Civil y Comercial de Córdoba, Morales, Ana María c/Frontera, María Vanesa s/ordinario - cumplimiento/resolución de contrato - recurso de apelación.

32 Véase Cámara de Apelaciones en lo Civil y Comercial de Pergamino, Aceitera Pergamino S. A. y otros c/Umere, Ramón y otro s/escrituración. 
- En un juicio sobre un contrato de locación, se consideró excesiva la pena del triple del alquiler mensual por cada mes de retraso en la restitución del inmueble (se la redujo al doble del alquiler). ${ }^{33}$

- En un juicio por cobro de expensas de un club de campo, la tasa de interés anual de una cláusula penal moratoria se redujo de un 180 a un 36\%.

- En una locación, el interés punitorio previsto para la mora en el pago de los alquileres se redujo del $120 \%$ anual al doble de la tasa activa promedio para operaciones de descuento de documentos a treinta días publicada por el Banco de la Nación Argentina, sin capitalización mensual de intereses. ${ }^{34}$

- Se declaró abusiva una cláusula penal por resolución accesoria de una compraventa inmobiliaria cuya pena ascendía al 50\% del precio. ${ }^{35}$ Se tuvo en cuenta que no llegó a entregarse la posesión y que entre la celebración del boleto y la resolución por incumplimiento transcurrieron solo nueve días. La pena se redujo en un $60 \%$, de modo que quedó fijada en un $20 \%$ del precio de la compraventa.

- En una locación inmobiliaria, se consideró excesiva una pena por mora en la restitución del inmueble equivalente al doble del alquiler convenido y que era acumulable con el pago de ese canon, con lo cual, en definitiva, el locatario estaba obligado a pagar el equivalente a tres alquileres mientras perdurase la ocupación indebida: dos como pena y uno como "canon". ${ }^{36}$ Se redujo la pena en un 50\%, con lo cual el locatario terminó pagando el doble del alquiler por el período de retención del inmueble: la mitad como pena y el resto como "canon". En suma, y más allá de las etiquetas escogidas por las partes, lo que se convino fue una pena por el triple del valor del alquiler y se la redujo en un tercio.

Veamos ahora algunos casos en los que se rechazó la petición del deudor:

- En un contrato de locación, se rechazó el pedido de reducción de la pena que se había previsto para la mora en la restitución del inmueble, que ascendía a dos veces y media el valor del canon locativo y era acumulable con el "canon" que el locatario debía pagar mientras perdurase la ocupación in-

33 Véase Cámara Nacional de Apelaciones en lo Civil, sala M, Zucchini de Morra, Josefina c/Quinteros, Miguel y otro s/Ejecución de alquileres. En rigor, se la había estipulado en un 10\% del alquiler por cada día de retraso (es decir, en el triple del precio de la locación: un 300\% mensual).

34 Véase Cámara de Apelaciones de Circuito de Santa Fe, Paludi, Silvia Guadalupe c/Monzón, Darío Ignacio y Otros s/sumaria.

35 Véase Cámara Nacional de Apelaciones en lo Civil, Maidana de Pis, Aurora F. c/Forlenza, Francisco L.

36 Véase Cámara 2a de Apelaciones en lo Civil, Comercial, Minas, de Paz y Tributaria de Mendoza, Sucesores de Resa, Domingo c/Bommecino María Esther y Ots. s/ejec. típica. 
debida ${ }^{37}$ Por cierto, si la ocupación era indebida, lo que el locatario pagaba no era un canon o alquiler, sino un resarcimiento por la retención ilegítima de la cosa, más allá de que su valor coincidiera con el del alquiler acordado. Al margen de esto, lo importante es que se validó que el deudor pagase el equivalente a tres veces y media el valor locativo del inmueble (dos y media como pena, y una como "canon locativo").

- En el marco de una locación de un salón de eventos, se consideró válida la cláusula penal compensatoria que el locador debía pagar al locatario, consistente en el doble del valor de la prestación incumplida. ${ }^{38}$ En concreto, apenas media hora después de celebrado el contrato y pagado el precio, el locador comunicó al locatario que le resultaría imposible poner a su disposición el local en la fecha convenida porque había sido reservado previamente por un tercero, circunstancia que por error no tuvo en cuenta al contratar. En rigor, la pena consistía en el doble del precio acordado. Esto es: no el doble de la prestación incumplida (la del locador), sino de la contraprestación que estaba a cargo del acreedor-locatario. Sin embargo, si suponemos que el alquiler representaba fielmente el valor de mercado de la prestación del locador (esto es, el valor locativo del salón), podemos concluir que, efectivamente, la pena acordada valía el doble de la prestación incumplida.

- En el marco de una compraventa, el tribunal validó el pacto por el cual el comprador tenía derecho a la restitución de la parte abonada del precio y al pago de otro tanto como pena si resolvía el contrato. ${ }^{39}$ Varios años después de la celebración del boleto, y ante el incumplimiento del vendedor de su obligación de escriturar, el comprador ejerció la facultad resolutoria y, por consiguiente, exigió el pago de la pena. En el fallo no se consigna qué parte del precio total representaba lo ya pagado, y si bien el comprador tuvo la posesión desde la firma del boleto (factor que, al menos en abstracto, podría haber gravitado a favor de la reducción), el tribunal tuvo en cuenta la cantidad de años de espera que debió soportar y la frustración de su proyecto familiar (el inmueble tenía destino de vivienda).

- En un juicio por cobro de alquileres, se validó una tasa de interés moratorio

37 Ver Cámara de Apelaciones en lo Civil, Comercial y Minería de San Juan, sala II, Cassab Hnos S.R.L. c/Telefónica Comunicaciones Personales S.A. s/cobro de pesos.

38 Ver Cámara Nacional de Apelaciones en lo Comercial, sala D, Braslavsky, Luis Néstor c/Madero Tango S.A. s/ordinario. Se morigeró, en cambio, la pena que, a su vez, estaba prevista para la mora en el pago de la pena, pero esto aquí no nos concierne.

39 Ver Cámara Nacional de Apelaciones en lo Civil, sala A, R., F. L. c/Manelma S. A. y otros s/daños y perjuicios. 
del $2 \%$ diario, ${ }^{40}$ es decir, no se consideró usuraria una tasa del $60 \%$ mensual. Y esto en el marco de un contrato de locación en perjuicio de su parte débil, el locatario. Hay que tener en cuenta, con todo, que el caso tuvo lugar en la década de 1980 (en concreto, en 1987), que estuvo atravesada por una inflación galopante que remató en la hiperinflación de 1989, que se llevó puesto al Gobierno de Alfonsín. De hecho, entre otras consideraciones, el tribunal destacó que era frecuente que se estipulasen tasas todavía más altas.

- En un juicio por pago de la pena prevista para la mora en la restitución de varios inmuebles dados en locación (uno de ellos) y comodato (el resto), el tribunal validó una pena diaria cuyo valor era el doble del precio de la locación por igual período. ${ }^{41}$

\subsection{Tiempo relevante}

\subsubsection{Regla general}

Para que la pena sea reducible, la desproporción debe existir en dos momentos:

- Cuando se celebra la cláusula penal.

- Cuando la pena se hace exigible. ${ }^{42}$

\subsubsection{Desproporción al tiempo en que se celebra la cláusula penal}

Normalmente, la celebración de la cláusula coincide con la del acto jurídico principal, pero puede no ser así. En cualquier caso, a los efectos de determinar si hay o no desproporción, lo que cuenta es lo primero: cuándo se estipuló la cláusula penal.

Ahora bien, ¿qué ocurre si la desproporción recién aparece después, cuando la pena se hace exigible? Por ejemplo, porque se ha disparado el valor del bien objeto de la pena. Distingamos dos cuestiones: ${ }^{43}$

1) No es aplicable el régimen de la cláusula penal excesiva -previsto en el artículo 794-, ya que la desproporción no ha existido en uno de los dos tiempos relevantes.

40 Véase Cámara Nacional de Apelaciones en lo Civil, sala C, Petriz, Adoración c/Casalotti, Héctor y otro.

41 Véase Cámara Nacional de Apelaciones en lo Civil, sala G, Robles, Roque c/Cabeda, Norberto O.

42 Véanse Brebbia (1995, p. 272); Iribarren y Zavala Rodríguez (2006, § III); Tavano (2001, § IV.4); Cámara Nacional de Apelaciones en lo Comercial, sala F, Luna Promotora S.R.L. s/quiebra s/inc. de revisión; Cámara 2a de Apelaciones en lo Civil, Comercial, Minas, de Paz y Tributaria de Mendoza, Sucesores de Resa, Domingo c/Bommecino María Esther y Ots. s/ejec. típica. La doctrina no es pacífica: para un sector, solo es preciso que la desproporción exista al tiempo en el que la pena es exigible (véase nota 47).

43 Véase Pizarro y Vallespinos (1999, p. 79). 
2) Eventualmente, podría llegar a aplicarse el régimen de la imprevisión -contenido en el artículo 1091 del CC- en la medida en la que concurran los requisitos legales correspondientes (onerosidad excesiva, alteración extraordinaria de las circunstancias, causa ajena a las partes, riesgo no asumido, etcétera). ${ }^{44}$

Lógicamente, la distinción tiene mucha importancia, dado que los requisitos de una y otra norma son muy distintos (por ejemplo, para aplicar el artículo 1091 no es necesario que el acreedor haya explotado la situación de inferioridad del deudor).

Un sector de la doctrina considera que solo es preciso que la desproporción exista al tiempo en que la pena es exigible. ${ }^{45}$ No estoy de acuerdo. En términos abstractos, la postura podría ser aceptable, pero no a la luz de lo dispuesto en nuestro derecho positivo. El tema está regulado con claridad como un caso de lesión (un vicio originario). Además, la referencia al carácter abusivo de la pena solo tiene sentido si el desequilibrio ya existe en el origen. Y esto no implica desamparar al deudor cuya pena se ha tornado excesivamente onerosa: existen otros dispositivos legales de los cuales puede echar mano.

\subsubsection{Desproporción al tiempo en que la pena es exigible}

Para reducir la pena, es necesario, además, que la desproporción subsista al tiempo en que se hace exigible. ${ }^{46}$ Solo en este momento es posible determinar si es proporcionada o no con el daño sufrido por el acreedor a raíz del incumplimiento de la obligación principal. ${ }^{47}$

Por lo tanto, no cabe reducir la pena si, por la razón que sea, la desproporción originaria ha desaparecido.

44 Véanse Brebbia (1995, p. 272); Kemelmajer de Carlucci (1981, pp. 120-121).

45 Véanse Calvo Costa (2019, § VI); Kemelmajer de Carlucci (2001, § 6); Tale (2009, § II).

46 Véanse Brebbia (1995, p. 272); Kemelmajer de Carlucci (1981, p. 113) ("La desproporción debe subsistir al momento de la aplicación de la cláusula [...]); Cámara Nacional de Apelaciones en lo Comercial, sala F, Luna Promotora S.R.L. s/quiebra s/inc. de revisión; Cámara 2a de Apelaciones en lo Civil, Comercial, Minas, de Paz y Tributaria de Mendoza, Sucesores de Resa, Domingo c/Bommecino Maria Esther y Ots. s/ejec. típica.

47 Véanse Cámara Nacional de Apelaciones en lo Comercial, sala F, Luna Promotora S.R.L. s/quiebra s/inc. de revisión; Cámara 2a de Apelaciones en lo Civil, Comercial, Minas, de Paz y Tributaria de Mendoza, Sucesores de Resa, Domingo c/Bommecino María Esther y Ots. s/ejec. típica; Kemelmajer de Carlucci (1981, p. 114). 


\subsection{Prueba}

La carga de la prueba de la desproporción pesa sobre el deudor de la pena. Al menos, esta es la regla que se ha considerado aplicable desde siempre.

Pero ¿es así realmente? Se supone que, al estipularse una cláusula penal, el acreedor se desentiende de la prueba del daño. Más todavía, se desentiende del daño, no solo de su prueba. Así lo prescribe el primer párrafo del artículo 794 del CC:

Ejecución. Para pedir la pena, el acreedor no está obligado a probar que ha sufrido perjuicios, ni el deudor puede eximirse de satisfacerla, acreditando que el acreedor no sufrió perjuicio alguno.

Sin embargo, todo esto se trastoca en virtud del segundo párrafo del mismo artículo. ${ }^{48}$ La razón es obvia:

- si la pena se puede reducir;

- si en muchos casos el daño es el principal factor entre los que determinan si debe o no ser reducida, entonces

- si bien, en principio, el daño es irrelevante, deja de serlo cuando hay que decidir si la pena debe o no ser reducida.

Refiero un caso que así lo muestra: ${ }^{49}$

- Se celebró una compraventa inmobiliaria.

- La operación incluía una cláusula penal moratoria que reforzaba la obligación de escriturar del vendedor.

- Este cayó en mora. De hecho, recién escrituró una vez que fue condenado judicialmente a hacerlo.

- En paralelo, el comprador promovió una acción tendiente al cobro de la pena moratoria.

- El tribunal hizo lugar a la demanda, pero redujo la pena en un 70\%.

No tengo elementos suficientes para analizar si en este caso la reducción fue o no ajustada a derecho, pero el punto al que quiero llegar es otro. Con todas las letras, el vocal preopinante sostuvo que

48 En este sentido, respecto a la norma análoga contenida en el CC (el artículo 656), véase Leiva Fernández y Agüero (1971).

49 Véase Cámara Nacional de Apelaciones en lo Civil, sala M, Carrió, Sergio Hernán c/Fideicomiso Recuperación Crediticia Ley 12726. 
[...] el Sr. Juez "a quo" obró equitativamente al reducir al 30\% el importe de la cláusula penal originariamente pactada, pues efectivamente el actor siempre tuvo la posesión del inmueble y en forma alguna probó los perjuicios por él alegados derivados del incumplimiento. ${ }^{50}$

Ciertamente, si la pena se estipuló de manera global para el incumplimiento de las obligaciones del vendedor, es razonable que se la reduzca si este solo incumplió su obligación de escriturar, no la de entregar la posesión de la cosa vendida. Pero lo que destaco es que el tribunal también justificó la reducción en el hecho de que el comprador no había probado los perjuicios derivados del incumplimiento.

En definitiva, lo que este caso tiene de especial no es tanto el criterio que aplica el tribunal (también los demás lo hacen), sino que lo explicita tan abiertamente. Y no es el único, por cierto. Refiero, en este sentido, el caso de una compraventa inmobiliaria finalmente resuelta por incumplimiento, cuya pena por resolución se redujo del 66 al 33\% del precio de venta. ${ }^{51}$ A la hora de justificar su decisión, el tribunal, entre otras razones, destacó que "tampoco se han probado fehacientemente los daños alegados sino que se ha invocado únicamente una imposibilidad de disponer del bien, la cual no importa prueba suficiente de los daños sufridos si el bien ha sido locado [...]". De nuevo: el punto no pasa por si correspondía o no efectuar la reducción, sino en la distribución de la carga de la prueba del daño, que explícitamente fue impuesta al acreedor. $^{52}$

En definitiva, el acreedor no siempre puede desentenderse del daño y su prueba. Puede hacerlo si el deudor no cuestiona la cláusula, pero, en caso contrario, más le vale probar el daño que ha sufrido para así acreditar que la pena no es evidentemente desproporcionada..$^{53}$ En suma, si bien no debe probar el daño para que la pena sea exigible, sí debe hacerlo para que, en su caso, no se la reduzcan..$^{54}$

50 Énfasis agregado.

51 Véase Cámara 5a de Apelaciones en lo Civil y Comercial de Córdoba, Morales, Ana María c/Frontera, María Vanesa s/ordinario - cumplimiento/resolución de contrato - recurso de apelación.

52 En cuanto a lo primero, el tribunal tuvo en cuenta que el vendedor pudo explotar la cosa vendida locándola en el ínterin entre su venta y su resolución posterior, lo que parece muy razonable.

53 Véase Azar y Mancini (2019, § IV).

54 Véase Leiva Fernández y Agüero (1971). 


\section{Conclusión}

A la hora de determinar si una cláusula penal es abusiva, se debe analizar si la pena es proporcionada con el valor de la prestación o del resarcimiento que viene a sustituir. Con lo cual, en definitiva, el acreedor no puede desentenderse del daño si la cláusula es cuestionada por el deudor.

En teoría, para reducir la pena también se requiere que el acreedor se haya aprovechado abusivamente de la situación del deudor. Pero no en la práctica, lo que pone en evidencia la centralidad del daño en esta materia: el sistema es mixto según la letra de la ley, pero objetivo en la praxis judicial, y el elemento objetivo se concentra, en definitiva, en el análisis de la proporcionalidad entre la pena y el daño.

\section{Bibliografía}

Ameal, O. J. y Belluscio, A. C. (Dirs.), Zannoni, E. A. (Coord.). (1981). Código Civil y leyes complementarias. Comentado, anotado y concordado (Tomo 3). Buenos Aires: Astrea.

Azar, A. M. y Mancini, M. P. (2019). Ponderación de los principios, valores y finalidades en la morigeración de las cláusulas penales. Thomson Reuters Información Legal, AR/ DOC/1648/2019.

Boffi Boggero, L. M. (1973). Tratado de las obligaciones (Tomo 2). Buenos Aires: Astrea.

Brebbia, R. (1995). Hechos y actos jurídicos (Tomo II). Buenos Aires: Astrea.

Calvo Costa, C. A. (2019). La cláusula penal y la problemática cuestión de la inmutabilidad. Thomson Reuters Información Legal, AR/DOC/702/2019.

Iribarren, G. O. y Zavala Rodríguez, C. J. (h.). (2006). Cláusula penal. Abuso del derecho (Autonomía de la voluntad. Limites. Facultades morigeradoras de los jueces. Actuación de oficio). Thomson Reuters Información Legal, AR/DOC/4285/2006.

Kemelmajer de Carlucci, A. (1981). La cláusula penal. Buenos Aires: Depalma.

Kemelmajer de Carlucci, A. (2001). Algunos aspectos de la inmutabilidad relativa de la cláusula penal. Thomson Reuters Información Legal, AR/DOC/21048/2001.

Kemelmajer de Carlucci, A. y Bueres, A. J. (Dir.), Highton, E I. (Coord.) (1998). Código Civil y normas complementarias. Análisis doctrinario y jurisprudencial (pp. 541-595) (2a ed., Tomo 2). Buenos Aires: Hammurabi.

Larenz, K. (1959). Derecho de obligaciones (Tomo II). Madrid: Revista de Derecho Privado.

Leiva Fernández, L. F. y Agüero, R. (1971). Incidencia de la reforma introducida por la ley 17.711 al principio de inmutabilidad en la cláusula penal (artículo 656, Código Civil). Thomson Reuters Información Legal, AR/DOC/6704/2011.

Llambías, J. J. (1983). Tratado de Derecho Civil. Obligaciones. (4a ed., Tomo I). Buenos Aires: Abeledo Perrot. 
Ossola, F. A. y Lorenzetti, R. L. (Dir.), De Lorenzo, M. F. y Lorenzetti, P. (Coords.). (2015), Código Civil y Comercial de la Nación comentado (Tomo V). Santa Fe: Rubinzal-Culzoni.

Papa, R. G. (2016). La ejecución de un boleto ante un fideicomiso inmobiliario. Thomson Reuters Información Legal, AR/DOC/3938/2016.

Piris, C. R. (2015). Crítica a la inmutabilidad relativa de la cláusula penal en el nuevo Código Civil y Comercial argentino. Gabilex: Revista del Gabinete Jurídico de Castilla-La Mancha, (3), 45-72.

Pizarro, R. D. y Vallespinos, C. G. (1999). Instituciones de Derecho Privado. Obligaciones (Tomo 3). Buenos Aires: Hammurabi.

Real Academia Española. (2014). Diccionario de la lengua española (23 a ed.).

Tale, C. (2009). La cláusula penal excesiva y la lesión en el contrato (Comparación entre ambas, reducción de oficio de la pena convenida y otras cuestiones controvertidas). Actualidad Jurídica, (6), 25-43.

Tavano, M. J. (2001). El principio de inmutabilidad de la cláusula penal: su revisión judicial. Thomson Reuters Información Legal, AR/DOC/20794/2001.

\section{Jurisprudencia citada}

Cámara 2a de Apelaciones en lo Civil, Comercial, Minas, de Paz y Tributaria de Mendoza, Sucesores de Resa, Domingo c/Bommecino María Esther y Ots. s/ejec. típica, 30/5/2014. Thomson Reuters Información Legal, AR/JUR/31779/2014.

Cámara 2a en lo Civil, Comercial y Minería de San Juan, Pereira Demarchi, José Luis c/Sancho, Francisco Javier y otros s/cobro de alquileres, 8/2/2013. Thomson Reuters Información Legal, AR/JUR/5653/2013.

Cámara 5a de Apelaciones en lo Civil y Comercial de Córdoba, Morales, Ana María c/Frontera, María Vanesa s/ordinario - cumplimiento / resolución de contrato - recurso de apelación, 25/11/2014. Thomson Reuters Información Legal, AR/JUR/68863/2014.

Cámara 5a de Apelaciones en lo Civil, Comercial, Minas, de Paz y Tributaria de Mendoza, Domus Laónica Argentina S.A. y Telecom Personal S.A. s/homologación de convenio (base cont. locac.), 26/8/2013. Thomson Reuters Información Legal, AR/JUR/51838/2013.

Cámara de Apelaciones de Circuito de Santa Fe, Paludi, Silvia Guadalupe c/Monzón, Dario Ignacio y Otros s/sumaria, 10/9/2015. Thomson Reuters Información Legal, AR/JUR/88623/2015.

Cámara de Apelaciones de Esquel, P., O. A. c/B., L. y otro s/resolución de contrato s/daños y perjuicios, 1/2/2016. Thomson Reuters Información Legal, AR/JUR/238/2016.

Cámara de Apelaciones en lo Civil y Comercial de Corrientes, sala IV, Meza, Inés Ana María c/Bahle Alicia Itatí, Cubilla Félix Ariel y Bahle Carlos Daniel s/cobro de pesos (sumarísimo), 22/10/2014. Thomson Reuters Información Legal, AR/JUR/58180/2014.

Cámara de Apelaciones en lo Civil y Comercial de Pergamino, Aceitera Pergamino S. A. y otros c/ Umere, Ramón y otro s/escrituración, 11/12/2014. Thomson Reuters Información Legal, AR/ JUR/80927/2014.

Cámara de Apelaciones en lo Civil, Comercial y Minería de San Juan, sala II, Cassab Hnos S.R.L. c/Telefónica Comunicaciones Personales S.A. s/cobro de pesos, 14/10/2015. Thomson Reuters Información Legal, AR/JUR/64042/2015. 
Cámara Nacional de Apelaciones en lo Civil, sala A, Damonte, Carlos H. c/García, Mabel S. y otros, 9/10/1995. Thomson Reuters Información Legal, AR/JUR/5/1995.

Cámara Nacional de Apelaciones en lo Civil, sala A, R., F. L. c/Manelma S. A. y otros s/daños y perjuicios, 11/09/2018. Thomson Reuters Información Legal, AR/JUR/53396/2018.

Cámara Nacional de Apelaciones en lo Civil, sala B, Cebrian Inmobiliaria SA c/Cebrian Hermanos SA s/cobro de sumas de dinero, 6/03/2017. Thomson Reuters Información Legal, AR/ JUR/16361/2017.

Cámara Nacional de Apelaciones en lo Civil, sala C, Maidana de Pis, Aurora F. c/Forlenza, Francisco L., 16/02/1988. Thomson Reuters Información Legal, AR/JUR/1142/1988.

Cámara Nacional de Apelaciones en lo Civil, sala C, Petriz, Adoración c/Casalotti, Héctor y otro, 20/06/1990. Thomson Reuters Información Legal, AR/JUR/416/1990.

Cámara Nacional de Apelaciones en lo Civil, sala F, Bulo, R. v. Comisión Municipal de la Vivienda, 3/08/1990. Thomson Reuters Información Legal, 70029314.

Cámara Nacional de Apelaciones en lo Civil, sala G, García Orosco, Benito c/Ollantay, S.A., 29/7/1980. La Ley Online, AR/JUR/2369/1980.

Cámara Nacional de Apelaciones en lo Civil, sala G, Robles, Roque c/Cabeda, Norberto O., 8/11/1990. Thomson Reuters Información Legal, AR/JUR/676/1990.

Cámara Nacional de Apelaciones en lo Civil, sala H, Rant Pazos, Pablo Ricardo c/Compañía Panamericana del Oeste SA s/daños y perjuicios, 12/02/2019. Thomson Reuters Información Legal, AR/JUR/723/2019.

Cámara Nacional de Apelaciones en lo Civil, sala I, D., A. J. c/D., M. A. s/ejecución de convenio, 2/10/2013. Thomson Reuters Información Legal, AR/JUR/98552/2013.

Cámara Nacional de Apelaciones en lo Civil, sala J, Celico, Pascual Leandro Hipólito c/Triex SA s/ daños y perjuicios, 17/12/2013. Thomson Reuters Información Legal, AR/JUR/94804/2013.

Cámara Nacional de Apelaciones en lo Civil, sala K, Coppola Libetta, Marco Fabio c/Oliva, Donald s/escrituración ordinario, 28/11/2018. Thomson Reuters Información Legal, AR/ JUR/79780/2018.

Cámara Nacional de Apelaciones en lo Civil, sala M, Carrió, Sergio Hernán c/Fideicomiso Recuperación Crediticia Ley 12726, 29/04/2009. Thomson Reuters Información Legal, AR/ JUR/9900/2009.

Cámara Nacional de Apelaciones en lo Civil, sala M, Zucchini de Morra, Josefina c/Quinteros, Miguel y otro s/Ejecución de alquileres, 25/03/2019. Thomson Reuters Información Legal, AR/JUR/3234/2019.

Cámara Nacional de Apelaciones en lo Comercial, sala D, Braslavsky, Luis Néstor c/Madero Tango S.A. s/ordinario, 4/12/2015. Thomson Reuters Información Legal, AR/JUR/65538/2015.

Cámara Nacional de Apelaciones en lo Comercial, sala F, Luna Promotora S.R.L. s/quiebra s/ inc. de revisión, 28/11/2013. Thomson Reuters Información Legal, AR/JUR/95981/2013.

Superior Tribunal de Justicia de la Provincia de Corrientes, Mutual del Personal de Agua y Energía Eléctrica de Corrientes s/concurso preventivo - inc. de revisión, 28/11/2013. Thomson Reuters Información Legal, AR/JUR/86389/2013. 
